\title{
Synthesis, Reactivity, Electrochemical Behavior, and Crystal Structure of a Family of Multivalent Metal Carbido-Carbonyl Clusters Based on the $\mathrm{Rh}_{10}(\mathrm{C})_{2} \mathrm{Au}_{4-6}$ Framework
}

\author{
Laura Cherchi, ${ }^{\dagger}$ Alessandro Fumagalli, ${ }^{* \dagger}{ }^{\dagger}$ Serena Fedi, ${ }^{\ddagger}$ Piero Zanello, ${ }^{*}{ }^{\ddagger}$ Fabrizia Fabrizi De Biani, ${ }^{\ddagger}$ \\ Franco Laschi, ${ }^{\ddagger}$ Luigi Garlaschelli, ${ }^{\S}$ Piero Macchi, ${ }^{\perp}$ and Angelo Sironi*, ${ }^{\circledR}$ \\ ${ }^{\dagger}$ Dipartimento di Scienze Teoriche e Applicate, Università dell'Insubria, via J. H. Dunant 3, 21100 Varese, Italy \\ ${ }^{\ddagger}$ Dipartimento di Chimica, Università di Siena, via A. De Gasperi 2, 53100 Siena, Italy \\ ${ }^{\S}$ Dipartimento di Chimica, Università di Milano, via G. Venezian 21, 20133 Milano, Italy \\ ${ }^{\perp}$ Department of Chemistry and Biochemistry, University of Bern, Freiestrasse 3, CH 3012 Bern, Switzerland
}

\section{Supporting Information}

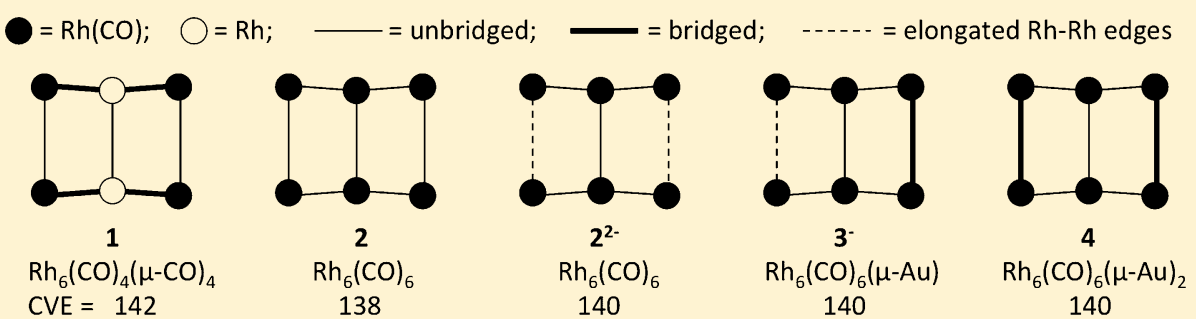

ABSTRACT: Six metal carbido-carbonyl clusters have been isolated and recognized as members of a multivalent family based on the dioctahedral $\mathrm{Rh}_{10}(\mathrm{C})_{2}$ frame, with variable numbers of $\mathrm{CO}$ ligands, $\mathrm{AuPPh}_{3}$ moieties, and anionic charge: $\left[\mathrm{Rh}_{10}(\mathrm{C})_{2}(\mathrm{CO})_{x}\left(\mathrm{AuPPh}_{3}\right)_{y}\right]^{n-}(x=18,20 ; y=4,5,6 ; n=0,1,2)$. Anions $\left[\mathrm{Rh}_{10}(\mathrm{C})_{2}(\mathrm{CO})_{18}\left(\mathrm{AuPPh}_{3}\right)_{4}\right]^{-}\left([2]^{-}\right)$and $\left[\mathrm{Rh}_{10}(\mathrm{C})_{2}(\mathrm{CO})_{18}\left(\mathrm{AuPPh}_{3}\right)_{4}\right]^{2-}\left([2]^{2-}\right)$ have been obtained by the reduction of $\left[\mathrm{Rh}_{10}(\mathrm{C})_{2}(\mathrm{CO})_{18}\left(\mathrm{AuPPh}_{3}\right)_{4}\right](2)$ under $\mathrm{N}_{2}$, while $\left[\mathrm{Rh}_{10}(\mathrm{C})_{2}(\mathrm{CO})_{18}\left(\mathrm{AuPPh}_{3}\right)_{5}\right]^{-}\left([3]^{-}\right)$was obtained from $\left[\mathrm{Rh}_{10}(\mathrm{C})_{2}(\mathrm{CO})_{20}\left(\mathrm{AuPPh}_{3}\right)_{4}\right](\mathbf{1})$ by reduction under a CO atmosphere. $[3]^{-}$can be better obtained by the addition of $\mathrm{AuPPh}_{3} \mathrm{Cl}$ to $[2]^{2-}$. $\left[\mathrm{Rh}_{10}(\mathrm{C})_{2}(\mathrm{CO})_{18}\left(\mathrm{AuPPh}_{3}\right)_{6}\right](4)$ is obtained from $[3]^{-}$and 2 as well by the reduction and subsequent addition of $\mathrm{AuPPh}_{3} \mathrm{Cl}$. The molecular structures of $[2]^{2-}\left(\left[\mathrm{NBu}_{4}\right]^{+}\right.$ salt), $[3]^{-}\left(\left[\mathrm{NMe}_{4}\right]^{+}\right.$salt), and 4 have been determined by single-crystal X-ray diffraction. The redox activities of complexes 1,2 and $[3]^{-}$have been investigated by electrochemical and electron paramagnetic resonance (EPR) techniques. The data from EPR spectroscopy have been accounted for by theoretical calculations.

\section{INTRODUCTION}

Interstitial or semiinterstitial atoms of the main-group elements $\left(\mathrm{E}=\mathrm{C}, \mathrm{N}, \mathrm{P}\right.$, etc.), establishing several $\mathrm{M}-\mathrm{E}_{\text {int }}$ interactions and contributing to the number of cluster valence electrons with no sterical requirements on the cluster surface, play an essential role in the stabilization of high-nuclearity metal carbonyl clusters. ${ }^{1}$ These compounds show also uncommon electrontransfer properties because of changes in the bonding character of the frontier molecular orbitals (MOs). ${ }^{2-7}$ In a previous paper, we have reported about two neutral isoskeletal mixedmetal carbido clusters with different numbers of coordinated carbonyl ligands, namely, $\left[\mathrm{Rh}_{10}(\mathrm{C})_{2}(\mathrm{CO})_{20}\left(\mathrm{AuPPh}_{3}\right)_{4}\right](\mathbf{1})$ and $\left[\mathrm{Rh}_{10}(\mathrm{C})_{2}(\mathrm{CO})_{18}\left(\mathrm{AuPPh}_{3}\right)_{4}\right](2){ }^{8}$ The two species are in equilibrium through the dissociation and association of two carbonyl ligands, according to eq 1 :

$$
\begin{aligned}
& {\left[\mathrm{Rh}_{10}(\mathrm{C})_{2}(\mathrm{CO})_{20}\left(\mathrm{AuPPh}_{3}\right)_{4}\right]} \\
& \quad \rightleftarrows\left[\mathrm{Rh}_{10}(\mathrm{C})_{2}(\mathrm{CO})_{18}\left(\mathrm{AuPPh}_{3}\right)_{4}\right]+2 \mathrm{CO}
\end{aligned}
$$

Thus, at room temperature, dissolution of 1 in 1 methylpyrrolidin-2-one (NMP) under a nitrogen atmosphere is enough to show, within minutes, the increasing formation of 2 with a change in color from dark-red to brown; under vacuum, $\mathbf{2}$ becomes the only species in solution. The process is reversed by the addition of $\mathrm{CO}(1-5 \mathrm{~atm})$ at room temperature. The different valence-electron counts of clusters 1 and 2 (142 and $138 \mathrm{CVE}$, respectively $)^{9,10}$ suggest a small highest occupied molecular orbital (HOMO)-lowest unoccupied molecular orbital (LUMO) gap and possibly multivalence. This was the starting point of our search for new species with possibly intermediate CVE numbers.

\section{RESULT AND DISCUSSION}

1. Multivalences of the $\mathrm{Rh}_{10}(\mathrm{C})_{2} \mathrm{Au}_{4-6}$ Clusters. We presumed that species 2 , having the lower CVE, would be the most suitable for electron addition, i.e., a reduction, and in fact

Received: August 9, 2011

Published: August 21, 2012 
we could obtain in sequence the monoanion $[2]^{-}$and the dianion $[2]^{2-}$ :

$$
\begin{aligned}
& {\left[\mathrm{Rh}_{10}(\mathrm{C})_{2}(\mathrm{CO})_{18}\left(\mathrm{AuPPh}_{3}\right)_{4}\right](\mathbf{2}, 138 \mathrm{CVE})} \\
& \quad \stackrel{\mathrm{e}^{\mathrm{e}}}{\rightarrow}\left[\mathrm{Rh}_{10}(\mathrm{C})_{2}(\mathrm{CO})_{18}\left(\mathrm{AuPPh}_{3}\right)_{4}\right]^{-}\left([\mathbf{2}]^{-}, 139 \mathrm{CVE}\right) \\
& \quad \stackrel{\mathrm{e}}{\rightarrow}\left[\mathrm{Rh}_{10}(\mathrm{C})_{2}(\mathrm{CO})_{18}\left(\mathrm{AuPPh}_{3}\right)_{4}\right]^{2-}\left([\mathbf{2}]^{2-}, 140 \mathrm{CVE}\right)
\end{aligned}
$$

( $\mathrm{e}^{-}=$sodium anthracene or benzophenone)

The two reduction steps, performed by the addition of titrated tetrahydrofuran (THF) solutions of sodium anthracene or benzophenone under a nitrogen atmosphere, can be clearly evidenced by the major changes of the IR spectra (Table 4). In fact, the stretching bands of both terminal and bridging $\mathrm{CO}$ groups are shifted to lower wavenumbers (ca. $20 \mathrm{~cm}^{-1}$ for each one-electron addition), due to increased $\mathrm{Rh}-\mathrm{CO}$ backdonation. Consistently with the electrochemical results (see later), the further addition of a reducing agent did not produce more reduced species. At variance with the parent compound 2, the electronic situation of dianion $[2]^{2-}$ appears quite stable with $140 \mathrm{CVE}$ in that no changes were observed in IR spectra either under prolonged static vacuum or under a $\mathrm{CO}$ atmosphere. In spite of several attempts of metathesis with many different bulky organic cations, we did not obtained any crystalline samples of monoanion $[2]^{-}$, while dianion $[2]^{2-}$ afforded crystalline samples of both the $\left[\mathrm{NBu}_{4}\right]^{+}$and $[\mathrm{PPN}]^{+}$ salts, allowing one to determine its crystal structure.

The chemical reduction of the neutral species 1 (142 CVE) under CO (1 atm) by sodium benzophenone gave IR evidence of the formation of what is possibly the $143 \mathrm{CVE}$ monoanion $[1]^{-}\left(\mathrm{Na}^{+}\right.$salt in NMP/THF: $2006 \mathrm{~s}, 1911 \mathrm{w}, 1850 \mathrm{~m}, 1835$ $\mathrm{ms}$ ). The species survived for a few hours in solution, but all attempts to isolate it led to decomposition. Further attempts to gain IR evidence of the pertinent dianion induced a fast sequence of reactions, affording, within minutes, the later recognized $\left[\mathrm{Rh}_{10}(\mathrm{C})_{2}(\mathrm{CO})_{18}\left(\mathrm{AuPPh}_{3}\right)_{5}\right]^{-}\left([3]^{-}\right)$. The key factor to produce such a gold-enriched compound must be the availability in the reaction medium of some "free" $\left(\mathrm{AuPPh}_{3}\right)^{+}$. In fact, it has been shown that, in the related species $\left[\mathrm{Rh}_{12}(\mathrm{C})_{2}(\mathrm{CO})_{23}\left(\mathrm{AuPPh}_{3}\right)\right]^{-}$, the $\left(\mathrm{AuPPh}_{3}\right)^{+}$moiety can be displaced by CO. ${ }^{11}$ Thus, in the present case, we propose the occurrence of the following sequence of reactions that upon passing through an intermediate and somewhat unstable dianion (ii) gives, by the addition of one gold fragment from a CO-induced partial decomposition of the starting material, the new species $[3]^{-}$:

$$
\begin{aligned}
& {\left[\mathrm{Rh}_{10}(\mathrm{C})_{2}(\mathrm{CO})_{20}\left(\mathrm{AuPPh}_{3}\right)_{4}\right](\mathbf{1})} \\
& \stackrel{\mathrm{e}^{-}, \mathrm{CO}}{\longrightarrow}\left\{\left[\mathrm{Rh}_{10}(\mathrm{C})_{2}(\mathrm{CO})_{20}\left(\mathrm{AuPPh}_{3}\right)_{4}\right]^{-}\right\}(\mathrm{i}) \\
& \stackrel{\mathrm{e}^{-}, \mathrm{CO}}{\longrightarrow}\left\{\left[\mathrm{Rh}_{10}(\mathrm{C})_{2}(\mathrm{CO})_{x}\left(\mathrm{AuPPh}_{3}\right)_{4}\right]^{2-}\right\}(\mathrm{ii}) \\
& \stackrel{\left(\mathrm{AuPPh}_{3}\right)^{+}}{\longrightarrow}\left[\mathrm{Rh}_{10}(\mathrm{C})_{2}(\mathrm{CO})_{18}\left(\mathrm{AuPPh}_{3}\right)_{5}\right]^{-} \\
& \left([\mathbf{3}]^{-}, 140 \mathrm{CVE}\right)
\end{aligned}
$$

The instability of the 143 and 144 CVE mono- and dianions (see the electrochemistry) can be due to the "oversaturation" of the orbitals available for multivalence and could imply the loss of at least one two-electron CO ligand to form the possible intermediate dianion (ii). As judged by IR spectroscopy, anion $[3]^{-}$is quite stable and unaffected by both a $\mathrm{CO}$ atmosphere and a prolonged static vacuum.
A more rational and high-yield synthesis of $[3]^{-}$was devised starting from dianion $[2]^{2-}$, according to reaction (4):

$$
\begin{gathered}
{\left[\mathrm{Rh}_{10}(\mathrm{C})_{2}(\mathrm{CO})_{18}\left(\mathrm{AuPPh}_{3}\right)_{4}\right]^{2-}\left([\mathbf{2}]^{2-}\right)+\mathrm{AuPPh}_{3} \mathrm{Cl}} \\
\rightarrow\left[\mathrm{Rh}_{10}(\mathrm{C})_{2}(\mathrm{CO})_{18}\left(\mathrm{AuPPh}_{3}\right)_{5}\right]^{-}\left([\mathbf{3}]^{-}\right)+\mathrm{Cl}^{-}
\end{gathered}
$$

Of the many different bulky organic cation derivatives produced, only the $\left[\mathrm{NMe}_{4}\right]^{+}$salt proved suitable in obtaining the X-ray crystal structure of anion $[3]^{-}$. Species $[3]^{-}$is quite stable in excess $\mathrm{AuPPh}_{3} \mathrm{Cl}$ and does not react even with $\left(\mathrm{AuPPh}_{3}\right)^{+}$(originated from the extemporaneous mixture of $\mathrm{AuPPh}_{3} \mathrm{Cl}$ and $\mathrm{AgBF}_{4}$ in THF); as a monoanion, it is not capable of undergoing electrophilic addition of the gold moiety. We could indeed obtain a six-gold species with a two-step procedure: the further reduction of $[3]^{-}$, followed by $\mathrm{AuPPh}_{3} \mathrm{Cl}$ addition. The reaction was also optimized starting from the neutral species 2 :

$$
\begin{aligned}
& {\left[\mathrm{Rh}_{10}(\mathrm{C})_{2}(\mathrm{CO})_{18}\left(\mathrm{AuPPh}_{3}\right)_{4}\right](\mathbf{2})} \\
& \quad \stackrel{2.5-3 \mathrm{e}^{-}}{\longrightarrow}[\mathbf{2}]^{2-} \text { in a reducing medium } \\
& \stackrel{2 \mathrm{AuPPh}_{3} \mathrm{Cl}}{\longrightarrow}\left[\mathrm{Rh}_{10}(\mathrm{C})_{2}(\mathrm{CO})_{18}\left(\mathrm{AuPPh}_{3}\right)_{6}\right](\mathbf{4})
\end{aligned}
$$

( $\mathrm{e}^{-}=$sodium anthracene or benzophenone)

An excess of reducing agent $(0.5-1 \mathrm{mmol})$ yields a solution of dianion $[2]^{2-}$ while maintaining the reducing medium. In this way, the addition of the $\left(\mathrm{AuPPh}_{3}\right)^{+}$moiety can go further to the six-gold derivative. The proposed reaction stoichiometry would indeed give an anion rather than the neutral species 4 . Very likely, the low solubility of $\mathbf{4}$ drives a redox equilibrium toward its formation and precipitation, in any case with moderate yields. It is worth noting that reversing the two steps of reaction (5) (i.e., adding the gold complex before of the reductant) results in the preferential reduction of gold with some phosphine set free; this causes side reactions with $\mathrm{CO}$ substitution on compound 2 .

Finally, we also considered the electron-rich species 1 (142 CVE) for oxidation, in order to obtain what would be, possibly, a rare example of a cationic cluster. We could indeed obtain evidence of the reaction with cerium(IV) (as nitrate or sulfate) in a mixture of $\mathrm{NMP} / \mathrm{MeOH}$, and a shift of the IR COstretching bands at higher wavenumbers of about $15 \mathrm{~cm}^{-1}$ $(2048 \mathrm{~s}, 1888 \mathrm{mw})$ was indicative at this regard. However, this species proved to be very unstable, and after some time, it apparently went back to the original oxidation state.

2. Crystal Structures of Species $[2]^{2-},[3]^{-}$, and 4. The three species share a $\mathrm{Rh}_{10} \mathrm{C}_{2}$ core, consisting of two edgesharing octahedra "filled" by interstitial carbon atoms, which is rather "uncommon", with the only other known examples being $\left[\mathrm{Ru}_{10} \mathrm{C}_{2}(\mathrm{CO})_{24}\right]^{2-12}$ and the parent compounds $\mathbf{1}$ and $2 .{ }^{8}$ However, a few "unfilled" bioctahedral clusters are also known, namely, $\mathrm{Ru}_{8} \mathrm{Pt}_{2}(\mathrm{CO})_{23}\left(\mu_{3}-\mathrm{H}\right){ }^{13}$ and $\mathrm{Ru}_{7} \mathrm{Pt}_{3}(\mathrm{CO})_{22}\left(\mu_{3}-\mathrm{H}\right) .{ }^{14}$

In $[2]^{2-}$, like in the parent clusters 1 and 2 , four gold atoms are triple bridging the (four) external triangular faces of the two tetrahedra generated by the edge-sharing octahedra. In species $[3]^{-}$, a fifth gold atom bridges one of the two edges of the $\mathrm{Rh}_{6} \mathrm{C}_{2}$ equatorial plane that are parallel to the internal one, shared by the two octahedra ( Rh2-Rh3 with reference to Figure 2 and the general labeling scheme in Figure 4). In 4, a sixth gold atom bridges the other one (Rh7-Rh8 in Figure 4).

The structures of the three species, as reported in Figures 1 $\left([2]^{2-}\right), 2\left([3]^{-}\right)$, and $3(4)$, show that the topology of the parent compound $\mathbf{2}$ is essentially retained: all of the molecules 


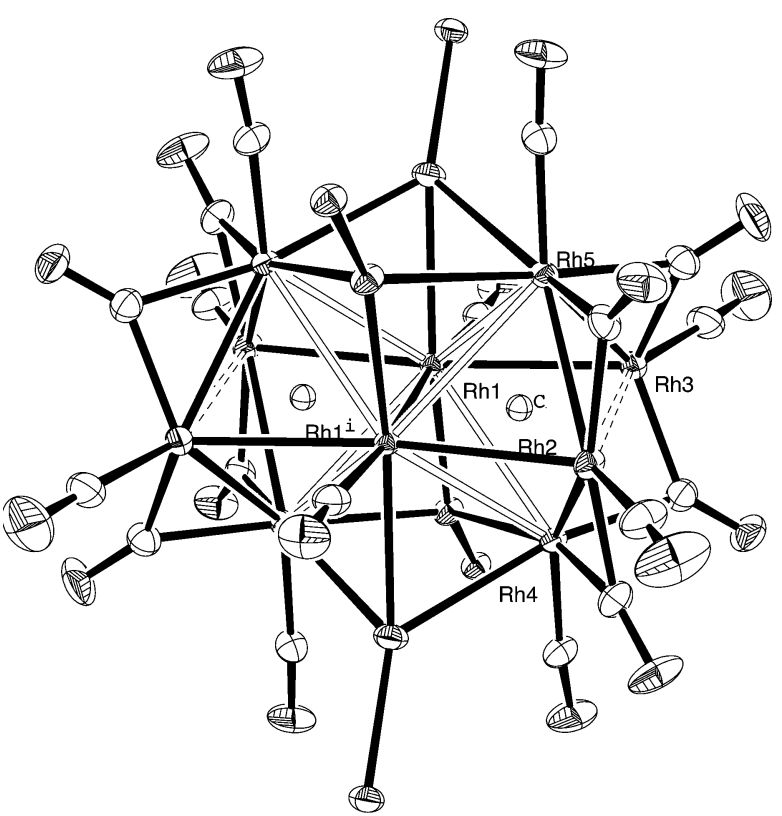

Figure 1. Structure of the $\left[\mathrm{Rh}_{10}(\mathrm{C})_{2}(\mathrm{CO})_{10}(\mu \text {-CO })_{8}\left\{\mu_{3}\right.\right.$-Au$\left.\left.\left(\mathrm{PPh}_{3}\right)\right\}_{4}\right]^{2-}$ dianion $\left([2]^{2-}\right)$, which lies about a center of symmetry.

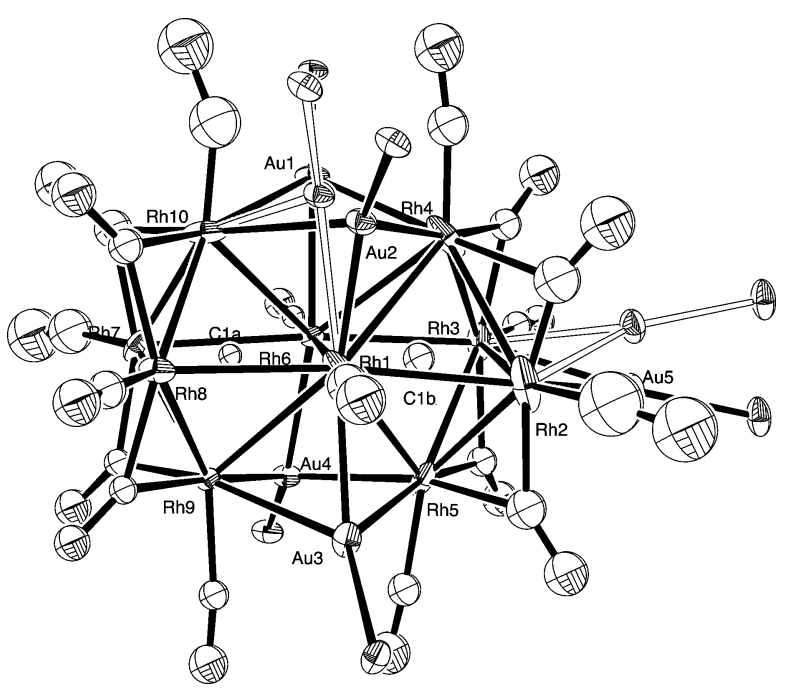

Figure 2. Structure of the $\left[\mathrm{Rh}_{10}(\mathrm{C})_{2}(\mathrm{CO})_{10}(\mu-\mathrm{CO})_{8}\left\{\mu_{3}-\mathrm{Au}\left(\mathrm{PPh}_{3}\right)\right\}\right.$ $\left.4\left\{\mu-\mathrm{Au}\left(\mathrm{PPh}_{3}\right)\right\}\right]^{-}$monoanion $\left([3]^{-}\right)$. Note that both Au2 and Au5 are disordered over two positions (highlighted by white bonds).

share a similar $\mathrm{Rh}_{10} \mathrm{C}_{2} \mathrm{Au}_{4}$ core. It is worth noting that both $[2]^{2-}$ and 4 lie about a center of symmetry while $[3]^{-}$is in a general position; at variance, the parent species 2 had a $C_{2 h}$ site symmetry. Therefore, 2 has the most symmetric $\mathrm{Rh}_{10} \mathrm{Au}_{n}$ metal cage, of $D_{2 h}$ symmetry, while those of $[2]^{2-}$ and 4 have $C_{2 h}$ symmetry; $[3]^{-}$has only $C_{s}$ symmetry.

In order to discuss the changes in the cluster stereochemistry upon the addition/removal of ligands or electrons, without bothering the different labeling (due to the different site symmetries of the different clusters), it is better to refer to Figure 4 and Table 1, where the distances are reported according to a common labeling scheme. The actual bond distances, those referring to the labeling of Figures 1-3, are reported in the Supporting Information (Tables S1-S3).

From the data in Table 1, it is clear that most of the relevant stereochemical transformations occur at the $\mathrm{Rh}_{6} \mathrm{C}_{2}$ equatorial

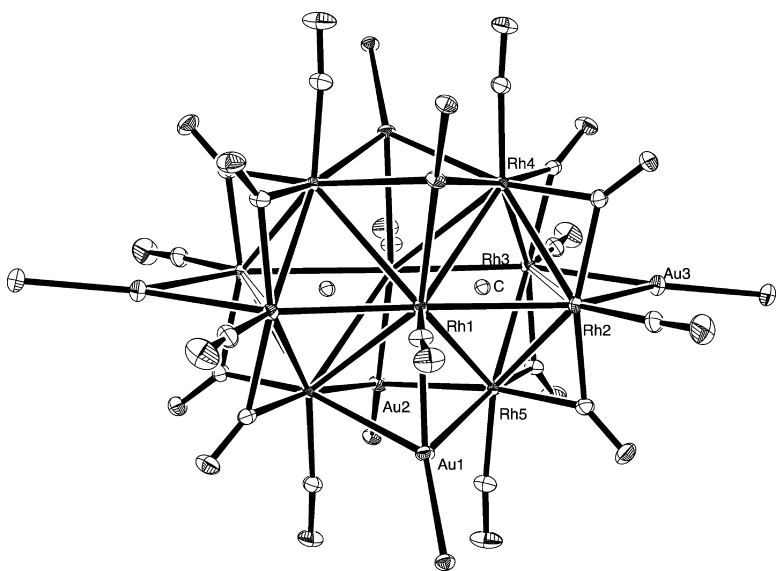

Figure 3. Structure of the $\left[\mathrm{Rh}_{10}(\mathrm{C})_{2}(\mathrm{CO})_{10}(\mu \text {-CO })_{8}\left\{\mu_{3}\right.\right.$-Au$\left.\left.\left(\mathrm{PPh}_{3}\right)\right\}_{4}\left\{\mu-\mathrm{Au}\left(\mathrm{PPh}_{3}\right)\right\}_{2}\right]$ molecule (4) which lies about a center of symmetry.

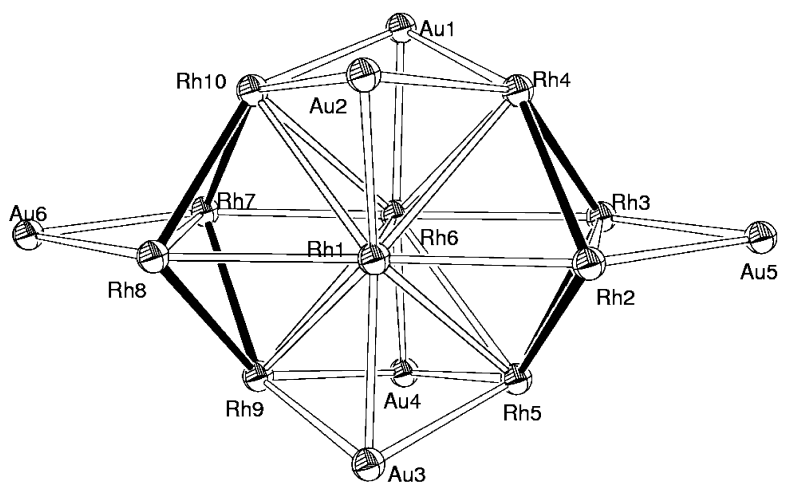

Figure 4. Labeling scheme used for the discussion through the text and the synoptical table of bond distances (Table 1). Solid bonds are bridged by carbonyl ligands in all five species.

plane, which appears to be the most "reactive" part of the $\mathrm{Rh}_{10} \mathrm{Au}_{4}$ cage. This behavior is further highlighted in Scheme 1, where the ligand connectivity in the equatorial plane is reported for the five species.

Indeed, $\mathbf{1}$ and $\mathbf{2}$ differ mainly in the distribution (and number) of the carbonyl ligands in that plane, while 2 and $[2]^{2-}$ share the ligand disposition, but in $[2]^{2-}$, two "lateral" edges ( $\mathrm{Rh} 2-\mathrm{Rh} 3$ and $\mathrm{Rh} 7-\mathrm{Rh} 8$ ) are elongated, possibly because of some localization of the two electrons in excess. Actually, the stepwise addition of electrophilic $\left[\mathrm{Au}\left(\mathrm{PPh}_{3}\right)\right]^{+}$ fragments occurs at these same edges, causing their shortening. This appears consistent with an electron transfer from a $\mathrm{Rh}-\mathrm{Rh}$ antibonding orbital to $\mathrm{Rh}-\mathrm{Au}$ bonding ones.

The transformations occurring in the equatorial plane, particularly those related to the lengthening/shortening of the lateral edges, are "transferred" to the whole cluster by the presence of eight, carbonyl-bridged, somewhat rigid $\mathrm{Rh}-\mathrm{Rh}$ bonds (located on the two "external" butterfly moieties highlighted as solid lines in Figure 4).

Indeed, upon passing from 2 to $[2]^{2-}$, we observe, together with the lengthening of the two lateral edges (highlighted as dashed bonds in Figure 1), that of the "internal" butterfly moieties of the two octahedra (highlighted as open bonds in Figure 1); this also results in a lengthening of the distances between the apical atoms of the two octahedra (Rh4-Rh10 and Rh5-Rh9). 
Table 1. Rh-Rh Distances $(\AA)$ within the considered structures with reference to the common labelling scheme in Figure 4

\begin{tabular}{llllll} 
& \multicolumn{1}{c}{$\mathbf{1}$} & \multicolumn{1}{c}{$\mathbf{2}$} & {$[\mathbf{2}]^{2-}$} & {$[3]^{-}$} & $\mathbf{4}$ \\
CVE & 142 & 138 & 140 & 140 & 140 \\
Rh1-Rh4 & 3.031 & 2.998 & 3.081 & 2.998 & 3.050 \\
Rh6-Rh9 & 3.031 & 2.998 & 3.081 & 3.170 & 3.050 \\
Rh1-Rh5 & 3.031 & 2.998 & 3.129 & 3.091 & 3.088 \\
Rh6-Rh10 & 3.031 & 2.998 & 3.129 & 3.009 & 3.088 \\
Rh1-Rh9 & 3.031 & 2.998 & 3.106 & 3.048 & 3.039 \\
Rh6-Rh4 & 3.031 & 2.998 & 3.106 & 2.951 & 3.039 \\
Rh1-Rh10 & 3.031 & 2.998 & 3.123 & 3.143 & 3.027 \\
Rh6-Rh5 & 3.031 & 2.998 & 3.123 & 3.048 & 3.027 \\
average & 3.031 & 2.998 & 3.110 & 3.057 & 3.051 \\
Rh1-Rh2 & 2.942 & 2.941 & 2.903 & 3.025 & 2.863 \\
Rh6-Rh7 & 2.942 & 2.941 & 2.903 & 2.938 & 2.863 \\
Rh1-Rh8 & 2.943 & 2.931 & 2.872 & 2.937 & 2.961 \\
Rh6-Rh3 & 2.943 & 2.931 & 2.872 & 2.951 & 2.961 \\
average & 2.942 & 2.936 & 2.887 & 2.963 & 2.912 \\
Rh2-Rh4 & 2.785 & 2.807 & 2.759 & 2.808 & 2.803 \\
Rh7-Rh9 & 2.785 & 2.807 & 2.759 & 2.772 & 2.803 \\
Rh2-Rh5 & 2.785 & 2.807 & 2.758 & 2.770 & 2.791 \\
Rh7-Rh10 & 2.785 & 2.807 & 2.758 & 2.767 & 2.791 \\
Rh3-Rh4 & 2.788 & 2.804 & 2.761 & 2.809 & 2.765 \\
Rh8-Rh9 & 2.788 & 2.804 & 2.761 & 2.788 & 2.765 \\
Rh3-Rh5 & 2.788 & 2.804 & 2.772 & 2.779 & 2.781 \\
Rh8-Rh10 & 2.788 & 2.804 & 2.772 & 2.762 & 2.781 \\
average & 2.786 & 2.805 & 2.762 & 2.782 & 2.785 \\
Rh1-Rh6 & 2.685 & 2.651 & 2.642 & 2.640 & 2.700 \\
Rh2-Rh3 & 3.094 & 3.087 & 3.376 & 3.039 & 3.116 \\
Rh7-Rh8 & 3.094 & 3.087 & 3.376 & 3.256 & 3.116 \\
Rh4-Rh10 & 3.626 & 3.521 & 3.962 & 3.922 & 3.649 \\
Rh5-Rh9 & 3.626 & 3.521 & 3.962 & 3.622 & 3.649 \\
Rh4-Rh5 & 4.055 & 4.063 & 4.001 & 4.092 & 4.078 \\
Rh9-Rh10 & 4.055 & 4.063 & 4.001 & 4.032 & 4.078 \\
\hline & & & & &
\end{tabular}

Upon passing from $[2]^{2-}$ to $[3]^{-}$, we observe, together with the shortening of the lateral edge capped by an incoming $\mathrm{Au}\left(\mathrm{PPh}_{3}\right)$ ligand $(\mathrm{Rh} 2-\mathrm{Rh} 3)$, a loss of symmetry of the whole cage and the shortening of one of the two distances between the apical atoms of the two octahedra (Rh5-Rh9).

Symmetry is, however, restored when, upon passing from $[3]^{-}$to 4 , the bridging by an $\mathrm{Au}\left(\mathrm{PPh}_{3}\right)$ ligand of the remaining lateral edge ( $\mathrm{Rh} 7-\mathrm{Rh} 8)$ determines its shortening, together with that of the remaining interapical distance (Rh9-Rh10).

3. Electrochemistry and Joint Electron Paramagnetic Resonance (EPR) Measurements. Figure 5 shows the cathodic cyclic voltammetric profile of $\mathbf{1}$ in an NMP solution under a $\mathrm{CO}$ atmosphere.

The percarbonylated complex 1 displays a first partially reversible reduction, followed by a second irreversible

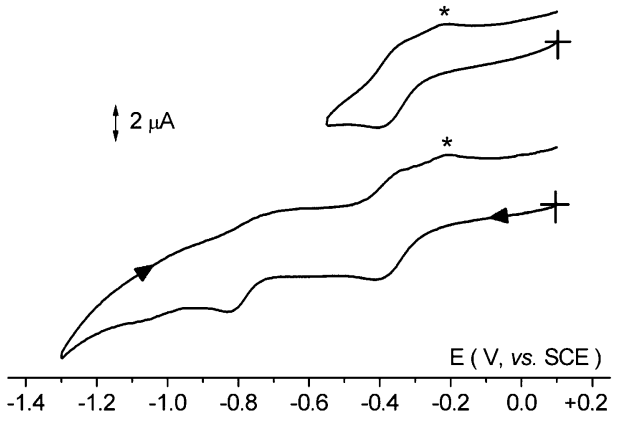

Figure 5. Cyclic voltammograms recorded at a gold electrode in an NMP solution of $1\left(0.6 \times 10^{-3} \mathrm{~mol} \mathrm{dm}{ }^{-3}\right)$. [ $\left.\mathrm{NBu}_{4}\right]\left[\mathrm{PF}_{6}\right]=$ supporting electrolyte $\left(0.2 \mathrm{~mol} \mathrm{dm}^{-3}\right)$. Scan rate $=0.2 \mathrm{~V} \mathrm{~s}^{-1}$.

reduction. The presence of fast chemical complications accompanying the first reduction is put in evidence either by the current ratio $i_{\mathrm{pr}} / i_{\mathrm{pf}}$, which substantially maintains around 0.7 independently from the scan rate, or by the appearance of the spurious (asterisked) peak in the backscan. Such a finding lends support to the above-cited pattern following chemical reduction.

As shown in Figure 6, under a $\mathrm{N}_{2}$ atmosphere, 2 exhibits in a 1,2-dichlorobenzene solution three reduction processes, the

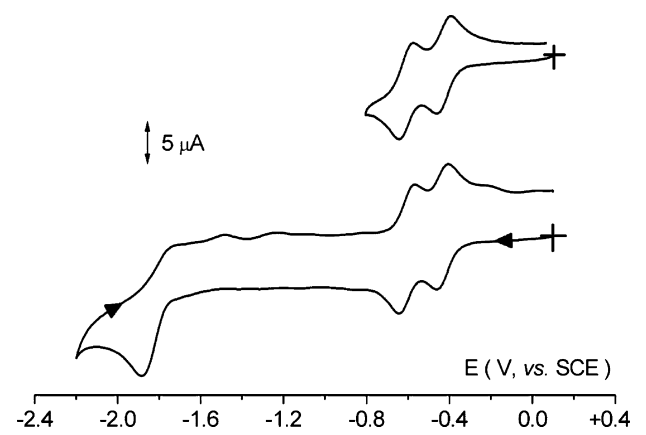

Figure 6. Cyclic voltammetric profiles of $2\left(1.4 \times 10^{-3} \mathrm{~mol} \mathrm{dm}^{-3}\right)$ in a 1,2-dichlorobenzene solution. Platinum working electrode. $\left[\mathrm{NBu}_{4}\right]$ $\left[\mathrm{ClO}_{4}\right]\left(0.1 \mathrm{~mol} \mathrm{dm}^{-3}\right)=$ supporting electrolyte. Scan rate $=0.2 \mathrm{~V} \mathrm{~s}^{-1}$.

first two of which display features of complete chemical reversibility in the cyclic voltammetric time scale. As a matter of fact, controlled potential coulometry proved that each of the two first reductions involves one electron per molecule. Analysis of the cyclic voltammograms with scan rates progressively increasing from 0.02 to $2 \mathrm{~V} \mathrm{~s}^{-1}$ confirmed the features of chemical reversibility in the cyclic voltammetric time scale $\left(i_{\mathrm{pc}} / i_{\mathrm{pa}} \approx 1 ; \Delta E_{\mathrm{p}} \approx 80 \mathrm{mV}\right) .{ }^{15}$ In addition, the mono- and dianions resulting from step-by-step exhaustive electrolysis proved to be quite stable, as confirmed by cyclic voltammetric

Scheme 1. Ligand Connectivity in the Equatorial Plane of the Five Species.

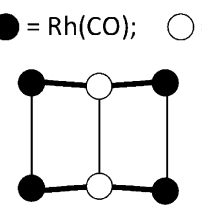

$\mathrm{Rh}_{6}(\mathrm{CO})_{4}(\mu-\mathrm{CO})_{4}$ $\mathrm{CVE}=142$

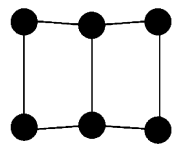

$\mathrm{Rh}_{6}(\mathrm{CO})_{6}$

138

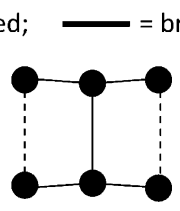

$2^{2-}$

$\mathrm{Rh}_{6}(\mathrm{CO})_{6}$

140

bridged;

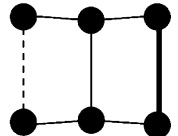

3-

$\mathrm{Rh}_{6}(\mathrm{CO})_{6}(\mu-\mathrm{Au})$

140

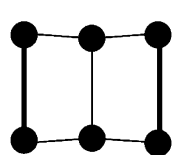

4

$\mathrm{Rh}_{6}(\mathrm{CO})_{6}(\mu-\mathrm{Au})_{2}$

140 
Table 2. Formal Electrode Potentials (V) and Peak-to-Peak Separations (mV) of the Redox Processes Exhibited by the Clusters under Study in Different Solvents

\begin{tabular}{|c|c|c|c|c|c|c|c|c|}
\hline cluster & $E_{(0 /+)}^{0 \prime}$ & $\Delta E_{\mathrm{p}}^{a}$ & $E_{(0 /-)}$ & $\Delta E_{\mathrm{p}}^{a}$ & $E_{(-/ 2-)}^{0 \prime}$ & $\Delta E_{\mathrm{p}}^{a}$ & $E_{\mathrm{p}(2-/ 4-)}{ }^{a, b}$ & solvent \\
\hline \multirow[t]{3}{*}{1} & $+0.69^{a, c}$ & 50 & $-0.53^{a, c}$ & 150 & & & & $1,2-\mathrm{C}_{6} \mathrm{H}_{4} \mathrm{Cl}_{2}$ \\
\hline & $+0.75^{a, c}$ & $80^{d}$ & $-0.39^{c}$ & 80 & $-0.88^{b, c}$ & & & $\mathrm{NMP}^{e}$ \\
\hline & & & $-0.39^{c}$ & 80 & & & & NMP/THF (1:1) \\
\hline \multirow[t]{2}{*}{2} & $+0.60^{a, c}$ & 150 & -0.40 & 100 & -0.60 & 60 & -1.76 & $1,2-\mathrm{C}_{6} \mathrm{H}_{4} \mathrm{Cl}_{2}$ \\
\hline & $+0.75^{a, b}$ & & -0.14 & 60 & -0.41 & 62 & -1.68 & NMP/THF (1:1) \\
\hline$[3]^{-}$ & & & $+1.28^{f}$ & 120 & -0.89 & 170 & & $1,2-\mathrm{C}_{6} \mathrm{H}_{4} \mathrm{Cl}_{2}$ \\
\hline
\end{tabular}

${ }^{a}$ Measured at $0.1 \mathrm{~V} \mathrm{~s}^{-1}$. ${ }^{b}$ Peak potential value for the irreversible process. ${ }^{c}$ Followed by chemical complications (see the text). ${ }^{d} \mathrm{Measured}$ at $2.0 \mathrm{~V}$ $\mathrm{s}^{-1} .{ }^{e} \mathrm{NMP}=1$-methylpyrrolidin-2-one. ${ }^{f}$ Oxidation process.

tests, which showed responses quite complementary to the original ones.

As far as the third reduction is concerned, it is confidently assigned to an almost completely irreversible two-electron process. We note that the electrochemical findings on the reduction pathways of complexes $\mathbf{1}$ and $\mathbf{2}$ are in agreement with the above-described experimental results from chemical reductions.

We point out that the two complexes also display a partially reversible oxidation, which, on the basis of the relative peak heights, are confidently attributed to one-electron processes (see Figure 1S in the Supporting Information).

The formal electrode potentials of the above-described electron-transfer processes of complexes $\mathbf{1}$ and $\mathbf{2}$ are compiled in Table 2, together with those of complex $[3]^{-}$discussed below.

The redox activity of $[3]^{-}$is illustrated in Figure 7 ; in a 1,2dichlorobenzene solution, the complex undergoes a substantially irreversible oxidation and a partially reversible reduction.

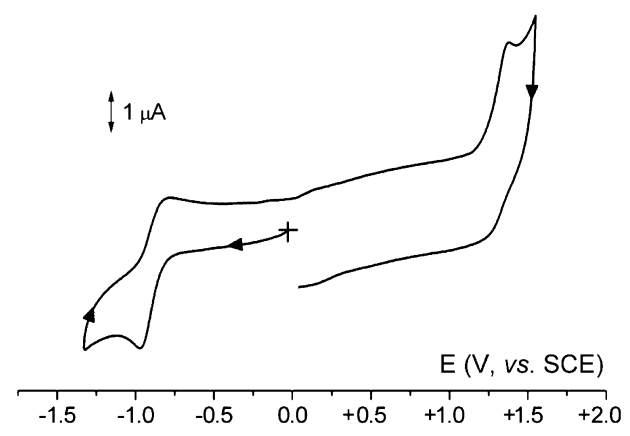

Figure 7. Cyclic voltammetric profile recorded at a glassy-carbon electrode in a saturated 1,2-dichlorobenzene solution of $[3]^{-}$under a $\mathrm{N}_{2}$ atmosphere. $\left[\mathrm{NBu}_{4}\right]\left[\mathrm{ClO}_{4}\right]\left(0.2 \mathrm{~mol} \mathrm{dm}{ }^{-3}\right)=$ supporting electrolyte. Scan rate $=0.02 \mathrm{~V} \mathrm{~s}^{-1}$.

Even if the negative potential value of the cathodic process prevented any reliable coulometric determination of the number of electrons involved, we tentatively assign it as a one-electron process.

With respect to the corresponding processes of 2 , the two processes are shifted toward more positive potentials and more negative potentials, respectively, thus indicating that the insertion of a further $\mathrm{AuPPh}_{3}$ group significantly increases the HOMO-LUMO gap with respect to 2 .

Figure 8 shows the anisotropic X-band EPR spectra of the electrogenerated monoanion $[2]^{-}$recorded in a 1,2 -dichlorobenzene frozen solution. The first, second, and third derivative experimental line shapes are characterized by an intense rhombic pattern, the high-field spectral components of which are significantly overlapped without any detectable resolution of the hyperfine (hpf) and superhyperfine (shpf) splittings (Au$197, I=3 / 2$, natural abundance $=100 \%$; Rh- $103, I=1 / 2$, natural abundance $=100 \%$; P-31, $I=1 / 2$, natural abundance $=100 \%$ ) under the limits of the very narrow linewidths. As shown, the pertinent multiple derivative line shapes have been adequately simulated. ${ }^{16}$ Here the $S={ }_{1}^{1} / 2$ Zeeman interaction is the basic magnetic term of the actual electron spin Hamiltonian as far as the narrow glassy signals are detected, while the corresponding linewidths $\left(\Delta H_{i}\right)$ play the crucial role for the EPR analysis of the magnetic hpf couplings (Au and $\mathrm{Rh}){ }^{17,18}$

Table 3 summarizes the paramagnetic features of $[2]^{-}$. The computed upper limits of the $a_{i}$ rhombic splittings are reported in relation to the related experimental $\Delta H_{i}$.

The computed $g_{i}$ values strongly attest to the contribution of the metal frame to the paramagnetic features $\left(g_{1}>g_{\text {free-electron }}=\right.$ $2.0023>g_{\mathrm{m}}, g_{\mathrm{h}}$ ), even if no direct evidence for $\mathrm{Au}$ (hpf), $\mathrm{Rh}$ (hpf), and P (shpf) magnetic coupling interactions with the unpaired electron has been detected. On this basis, only upper limits for the underlying (if any) hpf/shpf magnetic interactions can be evaluated, taking into account the experimental $\Delta H_{i}$.

On the other hand, we performed multiple derivativecomputed spectra, increasing the values of the underlying $a_{i}$ anisotropic parameters (only one magnetically active nucleus) or, alternatively, increasing the nuclearity of the magnetically coupled metal nuclei (two, three, four, ...). The best-fit results agree with the involvement of the nd metal orbitals in a significantly delocalized singly occupied molecular orbital (SOMO), basically Au/Rh constituted. Accordingly, the related $\mu_{\text {eff }}=1.72(1)$ confirms some orbital contribution to the paramagnetic features and related SOMO of $[2]^{-}$. As a further confirmation of the paramagnetic nature of the monoanion $[2]^{-}$, in a THF glassy solution $(T=100 \mathrm{~K})$, the monoanion exhibits a quite similar rhombic spectrum, even if the overall THF line shape is more noised, thus making the pertinent $\Delta H_{i}$ parameters less informative.

4. Extended Hückel (EH) Calculations. The narrowness of the EPR spectra of $[2]^{-}$is somewhat unexpected in a transition-metal cluster. For this reason, even if both the $g_{i}$ and $\mu_{\text {eff }}$ values are consistent with the hypothesis that the extra electron is delocalized on the metallic core, a doubt might arise concerning the option that it could instead be localized on the internal carbides. On the other side, the missing hpf/shpf features do not help this analysis. In this light, we undertook the theoretical analysis of the electronic structure of $[2]^{-}$. Realistically, given the dimensions of the system and the presence of many heavy atoms, the use of a semiempirical method seemed a reasonable choice. In fact, the proper theoretical treatment of EPR parameters is an extremely 

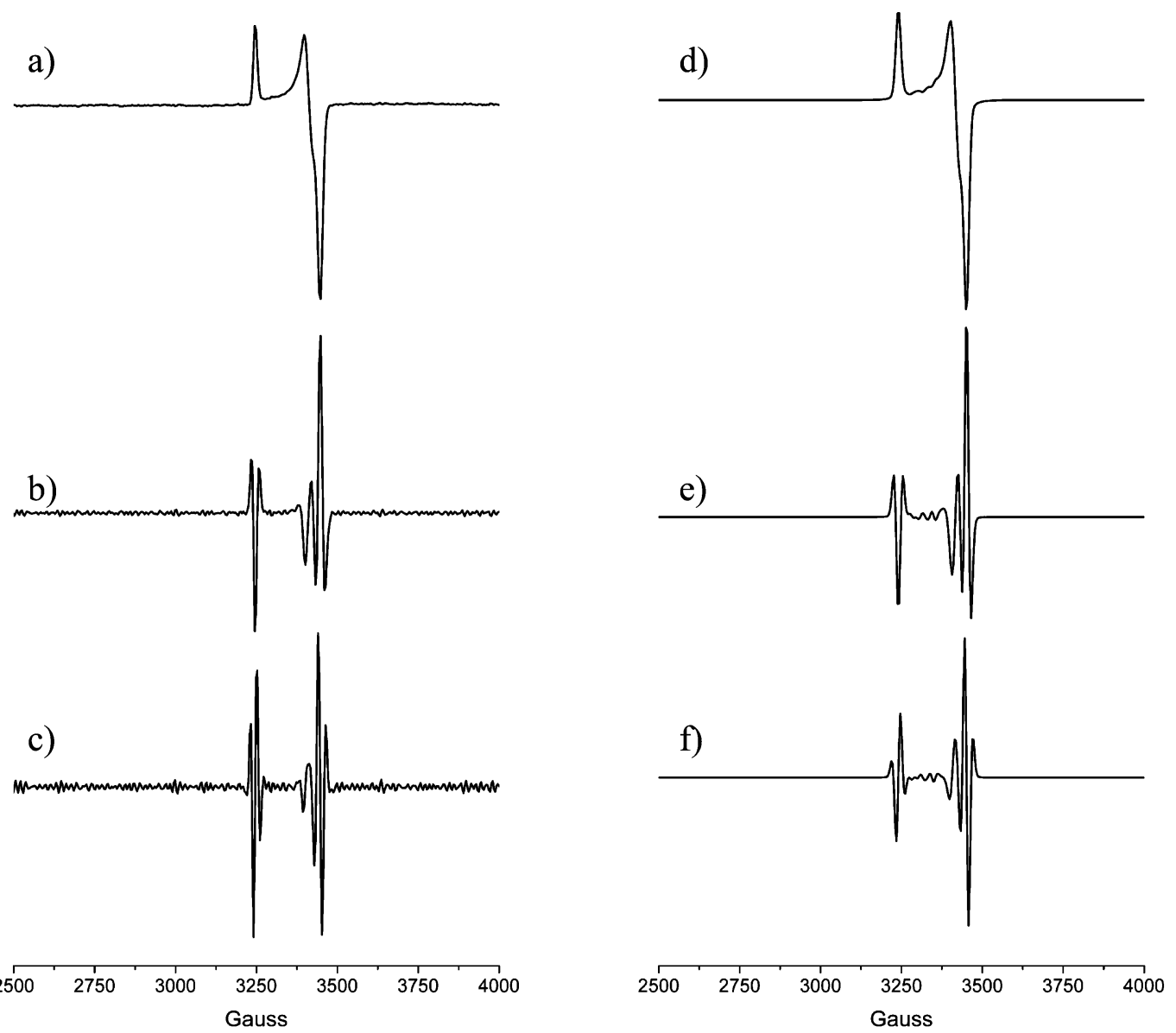

Figure 8. X-band EPR spectra of $[2]^{-}$in a 1,2-dichlorobenzene solution at $T=80 \mathrm{~K}:(\mathrm{a}-\mathrm{c})$ experimental first, second, and third derivative profiles; $(\mathrm{d}-\mathrm{f})$ simulated first, second, and third derivative profiles.

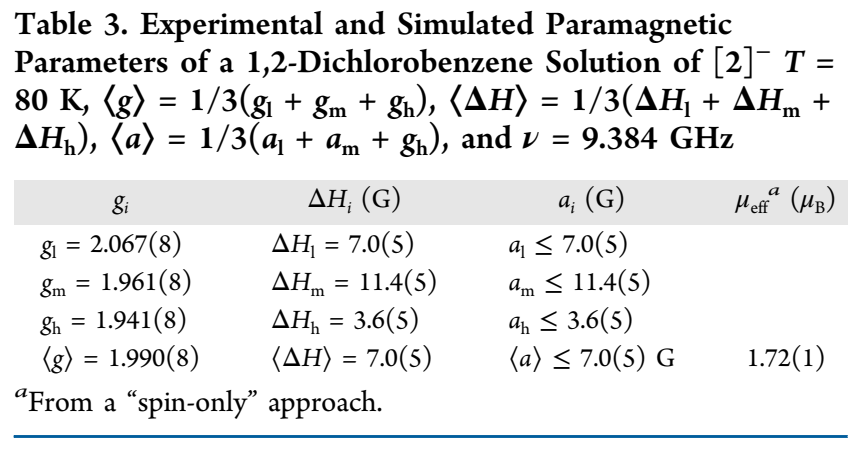

onerous task and is not affordable for a system of this size. ${ }^{19,20}$ Anyway, as will be illustrated in the following, a simple $\mathrm{EH}$ calculation works quite well in this case and is able to draw a reasonable portrait of the electronic structure of $[2]^{-}$as well as to give support to the experimental findings. ${ }^{21,22}$ Figure 9a shows the total density of states (DOS) for $[2]^{-}$, in which the discrete eigenvalues, calculated at the $\mathrm{EH}$ level, have been broadened with gaussians. ${ }^{23}$ This picture may be useful for a qualitative analysis of the MO composition in terms of the constituent chemical fragments. In fact, the projected DOS, also shown in Figure 9a, gives the contributions of $\mathrm{Rh}_{10}, \mathrm{Au}_{4}$, and $(\mathrm{C})_{2}$ (two internal carbides) fragments to the MOs. It is evident that the doubly and singly occupied frontier orbitals are decidedly localized on the $\mathrm{Rh}_{10}$ skeleton, while the contribution by the gold atoms and the internal carbides is almost negligible. The same is true for the LUMOs. Anyway, in this case, the $\mathrm{Rh}_{10}$ contribution to the MOs is smaller because the carbonyl component increases (the latter is not shown in the figure). To better compare the individual atom contribution to the MOs, we "normalized" the $\mathrm{Rh}_{10}, \mathrm{Au}_{4}$, and $(\mathrm{C})_{2}$ projected DOS, weighting the pertinent Gaussian curves (weight: $1 / 10,1 / 4,1 / 2$; Figure $9 \mathrm{~b}$ ). This procedure further confirms that the rhodium contribution to the SOMO is the main one. So, in spite of the narrowness of the EPR signal, this calculation confirms that the extra electron of $[2]^{-}$is localized on the metallic cluster, as is indeed suggested by the $g_{i}$ and $\mu_{\text {eff }}$ values. Figure 10a shows a picture of the SOMO from which some other conclusions can be extracted. In fact, eight of the rhodium atoms give the main contribution to this orbital, while the contributions from the two rhodium atoms of the octahedral shared edge (Rh1 and Rh6 with reference to Figure 4) are less important. This would naively explain, at the same time, both the small hpf (one electron is delocalized on several centers) and the quasi-axial shape of the EPR signal. Moreover, in accordance with the marked stability of $\mathbf{2}$ toward two-electron addition, the atomatom interactions in the SOMO are either nonbonding or weakly bonding. On the other side, in the LUMO shown in Figure $10 \mathrm{~b}$, there is an antibonding interaction between the two rhodium atoms of the octahedral shared edge, which could constitute the reason for the instability of the product arising from the third reduction of 2 . The presence of an important SOMO-LUMO energy gap explains the significant difference between the potentials of the second and third reduction 


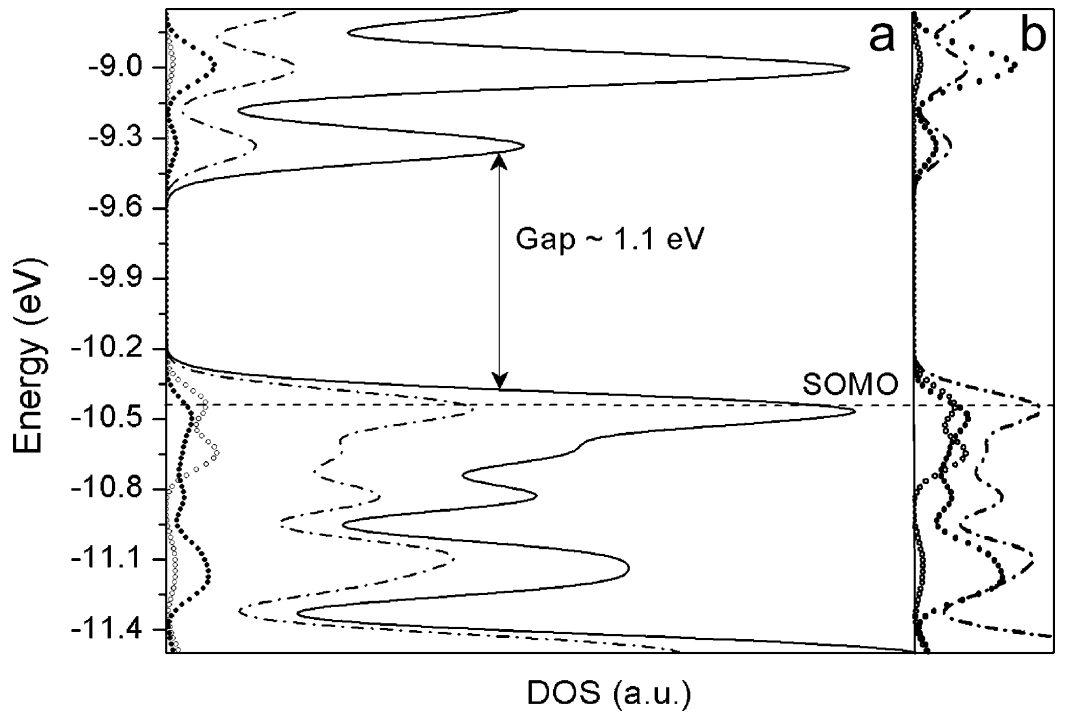

Figure 9. (a) DOS and projected DOS calculated for $[2]^{-}: \mathrm{Rh}_{10}(-\cdot-), \mathrm{Au}_{4}(\mathrm{O} O)$, and internal carbides $\mathrm{C}_{2}(\bullet \bullet \bullet)$. (b) Weighted projected DOS divided by the number of atoms in the fragment.
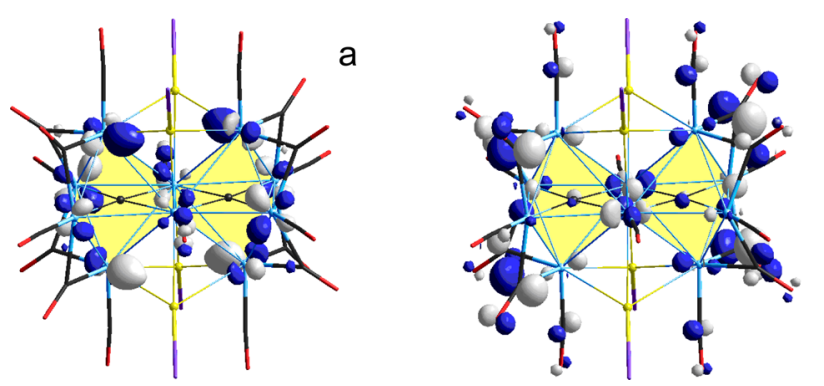

Figure 10. (a) SOMO and (b) LUMO obtained by EH calculations for $[2]^{-}$. Octahedra are colored, and hydrogen atoms are omitted to help with visualization.

processes and preludes to the experimentally observed diamagnetism of the dianion.

\section{EXPERIMENTAL SECTION}

All operations were carried out under $\mathrm{N}_{2}$ or $\mathrm{CO}$ where specified, with a standard Schlenk tube apparatus. ${ }^{24}$ Commercial anhydrous, inhibitor-free tetrahydrofuran (THF) was used. 1-Methylpyrrolidin2-one (NMP) and all other analytical-grade solvents were degassed in vacuum and stored under $\mathrm{N}_{2}$ with $3 \AA$ molecular sieves. $\left[\mathrm{Rh}_{10}(\mathrm{C})_{2}(\mathrm{CO})_{20}\left(\mathrm{AuPPh}_{3}\right)_{4}\right](\mathbf{1}),\left[\mathrm{Rh}_{10}(\mathrm{C})_{2}(\mathrm{CO})_{18}\left(\mathrm{AuPPh}_{3}\right)_{4}\right]$ (2), and $\left[\mathrm{Au}\left(\mathrm{PPh}_{3}\right) \mathrm{Cl}\right]^{25}$ were prepared by the published methods. IR spectra were recorded on a Nicolet Avatar 360 FT-IR spectrophotometer using $0.1 \mathrm{~mm} \mathrm{CaF}{ }_{2}$ cells previously purged with $\mathrm{N}_{2}$ or $\mathrm{CO}$. Elemental analyses were carried out by the staff of Laboratorio di Analisi of Dipartimento di Chimica - Milano.

1. Synthesis of [2] $]^{-}$as a [PPN] ${ }^{+}$Salt. $2(320 \mathrm{mg}, 0.094 \mathrm{mmol})$ was dissolved in a mixture of NMP $(2 \mathrm{~mL})$ and THF $(2 \mathrm{~mL})$ and treated at room temperature, under $\mathrm{N}_{2}$, with a freshly titrated THF solution of sodium anthracene $(0.11 \mathrm{M}, 0.9 \mathrm{~mL}, 1: 1$ molar ratio); after $15 \mathrm{~min}$, IR spectroscopic monitoring showed bands at 1987, 1904, 1834 , and $1815 \mathrm{~cm}^{-1}$. The $[\mathrm{PPN}] 2$ salt was precipitated by the dropwise addition of a solution of [PPN $] \mathrm{Cl}(69 \mathrm{mg})$ in 2-propanol $(15$ $\mathrm{mL})$. After $30 \mathrm{~min}$ of stirring, the solution was filtered and the precipitate washed with 2-propanol $(3 \times 1 \mathrm{~mL})$ and vacuum-dried. The crude product, redissolved in NMP $(3 \mathrm{~mL})$, was cautiously layered with 2-propanol $(15 \mathrm{~mL})$. When the diffusion was completed (ca. 2 weeks), the mother liquor was removed by a syringe and the precipitate thoroughly washed with 2-propanol and vacuum-dried. Yield: $120 \mathrm{mg}, 32 \%$ of an amorphous solid with a few sparse crystals that proved unsuitable for $\mathrm{X}$-ray diffraction studies. Anal. Found (calcd) for $\mathrm{C}_{128} \mathrm{H}_{90} \mathrm{Au}_{4} \mathrm{NO}_{18} \mathrm{P}_{6} \mathrm{Rh}_{10}$ : C, 38.87 (39.09); H, 2.45 (2.31); $\mathrm{N}, 0.51(0.36)$. The $\left[\mathrm{NMe}_{4}\right]^{+}$salt, obtained similarly by metathesis with $\mathrm{NMe}_{4} \mathrm{Cl}$, was not suitable for X-ray as well. Several other attempts of metathesis with many different bulky organic cations produced only amorphous derivatives. IR spectral data are given in Table 4.

2. Synthesis of $[2]^{2-}$ as a $[\mathrm{PPN}]^{+}$or $\left[\mathrm{NBu}_{4}\right]^{+}$Salt. $2(130 \mathrm{mg}$ $0.038 \mathrm{mmol})$, in a mixture of NMP $(1 \mathrm{~mL})$ and THF $(2 \mathrm{~mL})$, was treated at room temperature, under $\mathrm{N}_{2}$, with a freshly titrated THF solution of sodium anthracene $(0.05 \mathrm{M}, 1.6 \mathrm{~mL}, 1: 2$ molar ratio); after

Table 4. IR CO Stretching Bands $\left( \pm 2 \mathrm{~cm}^{-1}\right)$ of the Species $1,2,[2]^{-},[2]^{2-},[3]^{-}$, and 4

\begin{tabular}{|c|c|c|c|c|c|}
\hline species & CVEs & cation & solvent & $\begin{array}{l}\text { terminal } \\
\mathrm{COs}\end{array}$ & bridging $\mathrm{COs}$ \\
\hline 1 & 142 & & NMP & $\begin{array}{l}2024 \mathrm{~s}, \\
1930 \mathrm{w}\end{array}$ & $\begin{array}{l}1889 \mathrm{w}, 1871 \mathrm{~m} \\
1851 \mathrm{~ms}\end{array}$ \\
\hline 2 & 138 & & NMP & $\begin{array}{l}2012 \mathrm{~s}, \\
1938 \mathrm{w}\end{array}$ & $1863 \mathrm{~m}, 1836 \mathrm{~ms}$ \\
\hline \multirow[t]{3}{*}[2]{$^{-}$} & \multirow[t]{3}{*}{139} & $\mathrm{Na}^{+}$ & $\begin{array}{l}\text { NMP/ } \\
\text { THF }\end{array}$ & $1987 \mathrm{~s}$ & $\begin{array}{l}1902 \mathrm{w}, 1833 \mathrm{~m}, \\
1813 \mathrm{~m}\end{array}$ \\
\hline & & {$[\mathrm{PPN}]^{+}$} & NMP & $1987 \mathrm{~s}$ & $\begin{array}{l}1880 \mathrm{w}, 1834 \mathrm{~m} \\
1815 \mathrm{~m}\end{array}$ \\
\hline & & {$\left[\mathrm{NMe}_{4}\right]^{+}$} & NMP & $1988 \mathrm{~s}$ & $\begin{array}{l}1903 \mathrm{w}, 1836 \mathrm{~m} \\
1817 \mathrm{mw}\end{array}$ \\
\hline \multirow[t]{3}{*}[2]{$^{2-}$} & \multirow[t]{3}{*}{140} & $\mathrm{Na}^{+}$ & $\begin{array}{l}\text { NMP/ } \\
\text { THF }\end{array}$ & $\begin{array}{l}1974 \mathrm{~s} \\
1955 \mathrm{~s}\end{array}$ & $\begin{array}{l}1897 \mathrm{w}, 1817 \mathrm{~m}, \\
1795 \mathrm{~m}\end{array}$ \\
\hline & & {$\left[\mathrm{NBu}_{4}\right]^{+}$} & acetone & $\begin{array}{l}1973 \mathrm{~s} \\
1957 \mathrm{~s}\end{array}$ & $\begin{array}{l}1894 \mathrm{w}, 1817 \mathrm{~ms} \text {, } \\
1795 \mathrm{~m}\end{array}$ \\
\hline & & {$[\mathrm{PPN}]^{+}$} & NMP & $\begin{array}{l}1975 \mathrm{~s} \\
1957 \mathrm{~s}\end{array}$ & $\begin{array}{l}1895 \mathrm{w}, 1817 \mathrm{~ms} \text {, } \\
1794 \mathrm{~m}\end{array}$ \\
\hline \multirow[t]{6}{*}[3]{$^{-}$} & \multirow[t]{6}{*}{140} & {$\left[\mathrm{NMe}_{4}\right]^{+}$} & NMP & $1987 \mathrm{~s}$ & $\begin{array}{l}1904 \mathrm{w}, 1833 \mathrm{~ms}, \\
1810 \mathrm{~m}\end{array}$ \\
\hline & & {$\left[\mathrm{NBu}_{4}\right]^{+}$} & NMP & $1984 \mathrm{~s}$ & $\begin{array}{l}1902 \mathrm{w}, 1834 \mathrm{~ms}, \\
1813 \mathrm{~m}\end{array}$ \\
\hline & & {$\left[\mathrm{NBu}_{4}\right]^{+}$} & acetone & $1985 \mathrm{~s}$ & $\begin{array}{l}1902 \mathrm{w}, 1835 \mathrm{~ms}, \\
1813 \mathrm{~m}\end{array}$ \\
\hline & & {$\left[\mathrm{PPh}_{3} \mathrm{Bz}\right]^{+}$} & NMP & $1987 \mathrm{~s}$ & $\begin{array}{l}1902 \mathrm{w}, 1833 \mathrm{~m}, \\
1819 \mathrm{~m}\end{array}$ \\
\hline & & {$[\mathrm{PPN}]^{+}$} & NMP & $1986 \mathrm{~s}$ & $\begin{array}{l}1903 \mathrm{w}, 1833 \mathrm{~ms}, \\
1812 \mathrm{~m}\end{array}$ \\
\hline & & {$[\mathrm{PPN}]^{+}$} & acetone & $1986 \mathrm{~s}$ & $\begin{array}{l}1904 \mathrm{w}, 1835 \mathrm{~ms} \text {, } \\
1814 \mathrm{~m}\end{array}$ \\
\hline 4 & 140 & & NMP & $2002 \mathrm{~s}$ & $\begin{array}{l}1903 \mathrm{w}, 1849 \mathrm{mw}, \\
1820 \mathrm{~m}\end{array}$ \\
\hline
\end{tabular}


Table 5. Crystal Data and Structure Refinement for $[2]^{2-},[3]^{-}$, and $4^{a}$

\begin{tabular}{|c|c|c|c|}
\hline identification code & $\mathrm{Fu} 40 \mathrm{~b}\left([2]^{2-}\right)$ & Fu59 $\left([3]^{-}\right)$ & Fu58 (4) \\
\hline empirical formula & $\mathrm{C}_{132} \mathrm{H}_{148} \mathrm{Au}_{4} \mathrm{~N}_{2} \mathrm{O}_{20} \mathrm{P}_{4} \mathrm{Rh}_{10}$ & $\mathrm{C}_{117} \mathrm{H}_{95} \mathrm{Au}_{5} \mathrm{NO}_{19} \mathrm{P}_{5} \mathrm{Rh}_{10}$ & $\mathrm{C}_{138} \mathrm{H}_{108} \mathrm{Au}_{6} \mathrm{~N}_{2} \mathrm{O}_{20} \mathrm{P}_{6} \mathrm{Rh}_{10}$ \\
\hline $\mathrm{fw}$ & 4023.37 & 3987.72 & 4510.98 \\
\hline temperature, $\mathrm{K}$ & 293(2) & $100(2)$ & $150(2)$ \\
\hline wavelength, nm & 0.71073 & 0.71073 & 0.71073 \\
\hline cryst syst, space group & monoclinic, $P 21 / n$ & triclinic, $P \overline{1}$ & triclinic, $P \overline{1}$ \\
\hline$a, \AA$ & $15.675(3)$ & $14.862(7)$ & $14.7030(18)$ \\
\hline$b, \AA$ & $27.297(5)$ & $17.390(9)$ & $15.0640(19)$ \\
\hline$c, \AA$ & $17.166(3)$ & $24.298(12)$ & $15.2830(19)$ \\
\hline$\alpha, \operatorname{deg}$ & 90 & $88.542(8)$ & $90.9240(18)$ \\
\hline$\beta, \operatorname{deg}$ & $113.049(2)$ & $87.651(8)$ & $97.9550(18)$ \\
\hline$\gamma, \operatorname{deg}$ & 90 & $84.051(8)$ & $100.3750(18)$ \\
\hline volume, $\AA^{3}$ & $6759(2)$ & $6239(5)$ & $3294.7(7)$ \\
\hline$Z$, calcd density, $\mathrm{Mg} \mathrm{m}^{-3}$ & $2,1.977$ & $2,2.123$ & $1,2.274$ \\
\hline abs coeff, $\mathrm{mm}^{-1}$ & 5.618 & 7.261 & 8.004 \\
\hline$F(000)$ & 3880 & 3752 & 2124 \\
\hline cryst size, $\mathrm{mm}$ & $0.10 \times 0.15 \times 0.30$ & $0.05 \times 0.10 \times 0.15$ & $0.15 \times 0.15 \times 0.20$ \\
\hline $\begin{array}{l}\theta \text { range for data collection, } \\
\text { deg }\end{array}$ & $1.97-27.51$ & $1.59-25.24$ & $1.35-27.51$ \\
\hline limiting indices & $-20 \leq h \leq 20,-35 \leq k \leq 35,-22 \leq l \leq$ & $-17 \leq h \leq 17,-20 \leq k \leq 20,-29 \leq l \leq$ & $\begin{array}{r}-19 \\
19\end{array}$ \\
\hline reflns collected/unique & $56807 / 15498\left[R_{\text {int }}=0.0521\right]$ & $51029 / 22530\left[R_{\mathrm{int}}=0.0786\right]$ & $43253 / 15140\left[R_{\mathrm{int}}=0.0261\right]$ \\
\hline completeness, \% (to $\theta$, deg) & $99.7(27.5)$ & $99.8(25.2)$ & $99.8(27.5)$ \\
\hline abs corrn & $S A D A B S$ & $S A D A B S$ & $S A D A B S$ \\
\hline refinement method & full-matrix least squares on $\hat{F} 2$ & full-matrix least squares on $\hat{F} 2$ & full-matrix least squares on $\hat{F} 2$ \\
\hline data/restraints/param & $15498 / 5 / 745$ & $22530 / 12 / 568$ & $15140 / 8 / 787$ \\
\hline GOF on $F^{2}$ & 1.012 & 1.104 & 1.049 \\
\hline final $R$ indices $[I>2 \sigma(I)]$ & $\mathrm{R} 1=0.0360, \mathrm{wR} 2=0.0588$ & $\mathrm{R} 1=0.1034, \mathrm{wR} 2=0.2444$ & $\mathrm{R} 1=0.0253, \mathrm{wR} 2=0.0720$ \\
\hline$R$ indices (all data) & $\mathrm{R} 1=0.0679, \mathrm{wR} 2=0.0674$ & $\mathrm{R} 1=0.1600, \mathrm{wR} 2=0.2678$ & $\mathrm{R} 1=0.0346, \mathrm{wR} 2=0.0817$ \\
\hline$\underset{\AA^{-3}}{\text { largest diff peak and hole, e }}$ & 1.747 and -0.945 & 4.074 and -3.937 & 1.774 and -2.695 \\
\hline
\end{tabular}

15 min of stirring, IR spectroscopic monitoring showed the expected shift at lower wavenumbers of both the terminal and bridging carbonyl stretching bands. Crystalline $[\mathrm{PPN}]^{+}$and $\left[\mathrm{NBu}_{4}\right]^{+}$derivatives were directly obtained by slow-diffusion metathesis with respectively solutions of $[\mathrm{PPN}] \mathrm{Cl}$ or $\left[\mathrm{NBu}_{4}\right] \mathrm{Cl}$ in 2-propanol $(3 \mathrm{mg} / \mathrm{mL})$. When the diffusion was complete (ca. 3 weeks), the mother liquor was removed by a syringe and the precipitate thoroughly washed with 2propanol to remove the fine powder in a suspension accompanying the black crystalline product, which was vacuum-dried (yield 50-80 mg). Particularly, the $\left[\mathrm{NBu}_{4}\right]^{+}$salt obtained in this way proved suitable for the reported X-ray crystal structure that revealed two molecules of clathrated THF. Recrystallization from NMP/2-propanol yields nice black crystals containing two NMP clathrated molecules. Anal. Found (calcd) for $\mathrm{C}_{134} \mathrm{H}_{150} \mathrm{Au}_{4} \mathrm{~N}_{4} \mathrm{O}_{20} \mathrm{P}_{4} \mathrm{Rh}_{10}: \mathrm{C}$, 39.42 (39.47); $\mathrm{H}, 3.70$ (3.71); N, 1.62 (1.37). IR spectral data are given in Table 4.

3.a. Synthesis of $[3]^{-}$as a [PPN] $]^{+}$Salt, by the Reduction of 1 under CO. $1(143 \mathrm{mg}, 0.0414 \mathrm{mmol})$ in NMP $(1 \mathrm{~mL})$ and THF $(2$ $\mathrm{mL}$ ) at room temperature, under $\mathrm{CO}$, was treated with a freshly titrated solution of sodium anthracene $(0.05 \mathrm{M}, 1.6 \mathrm{~mL}, 1: 2$ molar ratio); after $15 \mathrm{~min}$, IR spectroscopic monitoring showed bands at $1986,1904,1835$, and $1814 \mathrm{~cm}^{-1}$. The $[\mathrm{PPN}]^{+}$salt was obtained by metathesis with $[\mathrm{PPN}] \mathrm{Cl}$ in 2-propanol. When the diffusion was complete (ca. 20 days), the mother liquor was removed by a syringe and the precipitate washed carefully with 2-propanol to remove the fine powder in a suspension accompanying the large crystals, which were vacuum-dried. The product is soluble in acetone and THF. Yield: $87.3 \mathrm{mg}$, 48\%. Anal. Found (calcd) for $\mathrm{C}_{146} \mathrm{H}_{105} \mathrm{Au}_{5} \mathrm{NO}_{18} \mathrm{P}_{7} \mathrm{Rh}_{10}$ : C, 41.2 (39.93); H, 2.18 (2.41); N, 0.4 (0.319). IR spectral data are given in Table 4.

3.b. Synthesis of $[3]^{-}$as a $[\mathrm{PPN}]^{+},\left[\mathrm{NMe}_{4}\right]^{+}$, or $\left[\mathrm{NBu}_{4}\right]^{+}$Salt, by the Reaction of Dianion [2] ${ }^{2-}$ with $\mathrm{AuPPh}_{3} \mathrm{Cl} .2$ (109 mg, 0.032 $\mathrm{mmol})$ in NMP $(2 \mathrm{~mL})$ and THF $(1 \mathrm{~mL})$ at room temperature, under a $\mathrm{N}_{2}$ atmophere, was treated with a freshly titrated solution of sodium anthracene in THF $(0.06 \mathrm{M}, 1.1 \mathrm{~mL}, 1: 2$ molar ratio). After $15 \mathrm{~min}$, when IR spectroscopic monitoring showed a reaction to the expected dianion [2] $]^{2-}$, the solution was treated with $\mathrm{AuPPh}_{3} \mathrm{Cl}(18 \mathrm{mg}, 0.034$ $\mathrm{mmol}$ ). After $1 \mathrm{~h}$ of stirring, the IR spectrum showed the expected IR of [3] $]^{-}$in NMP: 1987, 1904, 1849, 1831, and $1819 \mathrm{~cm}^{-1}$. The $[\mathrm{PPN}]^{+}$ salt was obtained by metathesis with $[\mathrm{PPN}] \mathrm{Cl}$ in 2-propanol. When the diffusion was complete (ca. 20 days), the mother liquor was removed by a syringe and the precipitate washed carefully with 2 propanol and vacuum-dried. Yield: ca. $50 \mathrm{mg}$. IR spectral data are given in Table 4. Metathesis was performed also with $\left[\mathrm{NMe}_{4}\right] \mathrm{Cl}$ or $\left[\mathrm{NBu}_{4}\right] \mathrm{Cl}$ in 2-propanol to obtain the respective crystalline derivatives. Unfortunately, all of these samples showed important decay during the $\mathrm{X}$-ray data collection and/or were affected by some disorder. The $\left[\mathrm{NMe}_{4}\right]^{+}$salt proved suitable for the best, although of fairly low quality, reported structure.

4. Synthesis of $\left[R h_{10}(C)_{2}(C O)_{18}\left(A_{u P P h}\right)_{6}\right]$ (4). 2 (42 mg, 0.012 $\mathrm{mmol})$ in NMP $(1.5 \mathrm{~mL})$ at room temperature, under $\mathrm{N}_{2}$, was treated, with stirring, with a freshly titrated THF solution of sodium anthracene (0.125 M, 0.3 mL, ca. 1:3 molar ratio); after $15 \mathrm{~min}$, IR spectroscopic monitoring showed a large band centered at 1966 (around dianion $\left.[2]^{2-}\right) . \mathrm{AuPPh}_{3} \mathrm{Cl}(15 \mathrm{mg}, 0.030 \mathrm{mmol}$ ) was added and the solution stirred for ca. $1 \mathrm{~h}$. The addition of water $(15 \mathrm{~mL})$ caused the precipitation of brown flakes; the precipitate was filtered and vacuum-dried, to yield a brown powder. Recrystallization was done by toluene dissolution $(3 \mathrm{~mL})$ and cautious layering of a mixture of 2-propanol and $n$-hexane $(2: 1,9 \mathrm{~mL})$. When the diffusion was complete (ca. 15 days), the mother liquor was removed by a syringe and the precipitate washed carefully with 2-propanol and vacuumdried. The product, mostly as a fine amorphous powder with only a 
few sparse black crystals, was insoluble in most common solvents except NMP or toluene, where it dissolves sparingly; this hindered any attempt of further recrystallization. Yield: $23.0 \mathrm{mg}$, 44\%. Anal. Found (calcd) for $\mathrm{C}_{128} \mathrm{H}_{90} \mathrm{Au}_{6} \mathrm{O}_{18} \mathrm{P}_{6} \mathrm{Rh}_{10}$ : C, 34.75 (34.65); H, 2.35 (2.10). $\mathrm{N}$, 0 (0). The tiny crystals providing the reported $\mathrm{X}$-ray structure contained two molecules of clathrated NMP. IR spectral data are given in Table 4.

5. X-ray Crystal Structure Determination of $\left[\mathrm{NBu}_{4}\right]_{2}\left[\mathrm{Rh}_{10}(\mathrm{C})_{2}(\mathrm{CO})_{18}\left(\mathrm{AuPPh}_{3}\right)_{4}\right] \cdot 2 \mathrm{THF}\left([2]^{2-}\right)$, [NMe 4$]-$ $\left[\mathrm{Rh}_{10}(\mathrm{C})_{2}(\mathrm{CO})_{18}\left(\mathrm{AuPPh}_{3}\right)\right] \cdot i \mathrm{PrOH}\left([3]^{-}\right)$, and $\left[\mathrm{Rh}_{10}(\mathrm{C})_{2}(\mathrm{CO})_{18}\left(\mathrm{AuPPh}_{3}\right)_{6}\right] \cdot 2 \mathrm{NMP}(4)$. Crystals were mounted on a glass fiber in air and collected either at room temperature $\left([2]^{2-}\right)$ or at low temperature $\left([3]^{-}, 100 \mathrm{~K} ; 4,150 \mathrm{~K}\right)$ on a Bruker AXS APEX2 CCD area-detector diffractometer, controlling the experimental temperature with an Oxford Cryosystems Cryostream 700 device. Crystal data are reported in Table 5. Graphite-monochromatized Mo $\mathrm{K} \alpha(\lambda=0.71073 \AA)$ radiation was used with the generator working at $50 \mathrm{kV}$ and $35 \mathrm{~mA}$. Orientation matrixes were initially obtained from least-squares refinement on ca. 300 reflections measured in three different $\omega$ regions, in the range $0<\theta<23^{\circ}$; cell parameters were optimized on the position, determined after integration, of ca. 8000 reflections. The intensity data were retrieved in the full sphere, within the $\theta$ limits reported in Table 5, from 2400 frames collected with a sample-detector distance fixed at $5.0 \mathrm{~cm}\left(40 \mathrm{~s}\right.$ frame ${ }^{-1} ; \omega$ scan method, $\left.\Delta \omega=0.3^{\circ}\right)$. An empirical absorption correction was applied $\left(S A D A B S^{26}\right)$. The structures were solved by direct methods $\left(S I R 97^{27}\right)$ and refined with full-matrix least squares (SHELX97) ${ }^{28,29}$ Anisotropic temperature factors were assigned to metal, phosphorus, carbide, and carbonyl atoms in $[2]^{2-}$ and $\mathbf{4}$, while in $[3]^{-}$, which is rather affected by ligand disorder, only to metal and phosphorus atoms. Hydrogen atoms were riding on their carbon atoms.

The disordered $i \mathrm{PrOH}$ solvent molecule present in the crystal structure of $[3]^{-}$was removed with the usage of PLATON/SQUEEZE.

6. Electrochemistry and EPR Spectroscopy. Anhydrous $99 \%$ 1,2-dichlorobenzene and absolute NMP were Aldrich products. Anhydrous 99.9\% HPLC-grade THF (Aldrich) was distilled in the presence of sodium before use. Fluka $\left[\mathrm{NBu}_{4}\right]\left[\mathrm{PF}_{6}\right]$ and $\left[\mathrm{NBu}_{4}\right]\left[\mathrm{ClO}_{4}\right]$ (electrochemical grade) were used as supporting electrolytes. Cyclic voltammetry was performed in a three-electrode cell containing the working electrode surrounded by a platinum-spiral counter electrode and the reference electrode saturated calomel electrode (SCE) mounted with a Luggin capillary. Platinum, gold, or glassy-carbon electrodes were used as working electrodes. Controlled potential coulometry was performed in an $\mathrm{H}$-shaped cell with anodic and cathodic compartments separated by a sintered-glass disk. The working macroelectrode was a platinum gauze; a mercury pool was used as the counter electrode. A BAS $100 \mathrm{~W}$ electrochemical analyzer was used as the polarizing unit. All of the potential values are referred to the SCE reference electrode. Under the present experimental conditions and at $293 \mathrm{~K}$, the one-electron oxidation of ferrocene occurs at $E^{0 \prime}=+0.55 \mathrm{~V}$ in NMP, at $E^{0 \prime}=+0.55 \mathrm{~V}$ in 1,2 dichlorobenzene, and at $E^{\circ \prime}=+0.57 \mathrm{~V}$ in NMP/THF (1:1).

Electron spin resonance spectra were recorded with a ER $200 \mathrm{D}$ SRC Bruker spectrometer operating at X-band frequencies using a HS Bruker rectangular cavity. The control of the operational frequency was obtained with a Hewlett-Packard X 5-32 B wavemeter, and the magnetic field was calibrated with a 1,1-diphenyl-2-picrylhydrazyl (DPPH) radical as a suitable field marker. The $g$ values are referred to DPPH $(g=2.0036)$ used as an external standard reference.

7. EH Calculations. EH calculations and fragment analysis have been performed with the program package $\left(C A C A O^{21}\right)$ and repeated by using HyperChem ${ }^{22}$ to obtain better quality drawings of the MOs. Both programs have given very similar results. Even if the experimental geometry of $[\mathbf{2}]^{-}$is not available, it may be foreseen that it is intermediate between that of the neutral and dianion derivatives. The calculations have been repeated for both $[\mathbf{2}]$ and $[\mathbf{2}]^{2-}$, obtaining similar results. In fact, the orbital energies may vary, but their relative order remains unaltered. The results discussed here refer to the case in which the experimental geometry of $[\mathbf{2}]^{2-}$ has been used to model $[2]^{-}$. The triphenylphosphine ligands have been modeled by simple
$\mathrm{PH}_{3}$. DOS has been built by broadening the eigenvalues with a normal Gaussian distribution, ${ }^{23}$ while projected DOS have been obtained by weighting these curves with fragment percent contributions. The software Origin 8.0 has been used for this purpose. ${ }^{30}$

\section{CONCLUSIONS}

Chemical reactivity results closely match with the redox propensity as measured in the electrochemical experiments. Thus, the instability of the $143 \mathrm{CVE}$ monoanion $[\mathbf{1}]^{-}$and the nonexistence of a related 144 CVE dianion have been confirmed in the electrochemistry of complex 1 . The two stable and characterized anions $[2]^{-}(139 \mathrm{CVE})$ and $[2]^{2-}(140$ CVE) correspond to the two solely reversible reduction steps found for compound 2. EPR spectra of the paramagnetic [2]and theoretical calculations indicate that the first electron addition to 2 enters a $\mathrm{MO}$ essentially delocalized on the $\mathrm{Rh}_{10}$ core. This is in full agreement with the structural findings showing that this portion of the metal cluster is the same one sensitive to variation of the cluster valence electrons.

\section{ASSOCIATED CONTENT}

\section{S Supporting Information}

Cyclic voltammograms (Figure 1S), refined atom coordinates and anisotropic thermal parameters in CIF format, and listings of selected bond parameters (Tables S1-S3). This material is available free of charge via the Internet at http://pubs.acs.org.

\section{AUTHOR INFORMATION}

\section{Corresponding Author}

*E-mail: alessandro.fumagalli@uninsubria.it (A.F., synthesis and reactivity), zanello@unisi.it (P.Z., electrochemistry and EPR), angelo.sironi@unimi.it (A.S., structural considerations). Tel: +390332 421548 (A.F.). Fax: +39 0332421554 (A.F.).

\section{Notes}

The authors declare no competing financial interest.

\section{ACKNOWLEDGMENTS}

P.Z. gratefully acknowledges the financial support of MIUR (PRIN 2008).

\section{REFERENCES}

(1) Fumagalli, A.; Della Pergola, R. In Metal Clusters in Chemistry; Braunstein, P., Oro, L. A., Raithby, P. R., Eds.; Wiley-VCH: Weinheim, Germany, 1999; Vol. 1, pp 323-347.

(2) Collini, D.; Femoni, C.; Iapalucci, M. C.; Longoni, G.; Svensson, P. H.; Zanello, P. Angew. Chem., Int. Ed. 2002, 41, 3685-3688.

(3) Albano, V. G.; Demartin, F.; Iapalucci, M. C.; Laschi, F.; Longoni, G.; Sironi, A.; Zanello, P. J. Chem. Soc., Dalton Trans. 1991, 739-748.

(4) Zanello, P. Physical Organometallic Chemistry. In Unusual Structures and Physical Properties in Organometallic Chemistry; Gielen, M., Willem, R., Wrackmeyer, B., Eds.; John Wiley: Chichester, U.K., 2002; Vol. 3, pp 1-49.

(5) Fumagalli, A.; Ulivieri, P.; Costa, M.; Crispu, O.; Della Pergola, R.; Fabrizi de Biani, F.; Laschi, F.; Zanello, P.; Macchi, P.; Sironi, A. Inorg. Chem. 2004, 43, 2125-2131.

(6) Costa, M.; Della Pergola, R.; Fumagalli, A.; Laschi, F.; Losi, S.; Macchi, P.; Sironi, A.; Zanello, P. Inorg. Chem. 2007, 46, 552-560.

(7) Della Pergola, R.; Bruschi, M.; Fabrizi de Biani, F.; Fumagalli, A.; Garlaschelli, L.; Laschi, F.; Manassero, M.; Sansoni, M.; Zanello, P. C.R. Chim. 2005, 8, 1850-1855.

(8) Fumagalli, A.; Martinengo, S.; Albano, V. G.; Braga, D.; Grepioni, F. J. Chem. Soc., Dalton Trans. 1993, 2047-2052.

(9) The count, considering the ligand contribution, is done as follows: $\mathrm{CVE}=9(\mathrm{Rh})+1(\mathrm{Au})+4\left(\mathrm{C}_{\text {interst }}\right)+2(\mathrm{CO})+1($ anionic charge). 
(10) According to Mingos' rule for condensed polyhedra, a bioctahedron should have 138 CVE. Mingos, D. M. P. Acc. Chem. Res. 1984, 17, 311-319.

(11) Albano, V. G.; Fumagalli, A.; Grepioni, F.; Martinengo, S.; Monari, M. J. Chem. Soc., Dalton Trans. 1994, 1777-1782.

(12) (a) Hayward, C. M.; Shapley, J. R.; Churchill, M. R.; Bueno, C.; Rheingold, A. L. J. Am. Chem. Soc. 1982, 104, 7347-7349. (b) Churchill, M. R; Bueno, C.; Rheingold, A. L. J. Organomet. Chem. 1990, 395, 85-103. (c) Bruce, M. I.; Zaitseva, N. N.; Skelto, B. W.; White, A. H. J. Chem. Soc., Dalton Trans. 2002, 3879-3885.

(13) Adams, R. D.; Li, Z.; Lii, J. C.; Wu, W. J. Am. Chem. Soc. 1992, $114,4918-4920$.

(14) Adams, R. D.; Li, Z.; Lii, J. C.; Wu, W. Organometallics 1992, 11, 4001-4009.

(15) (a) Zanello, P. Inorganic Electrochemistry. Theory, Practice and Application; RSC: Cambridge, UK, 2003. (b) Zanello, P.; Nervi, C.; Fabrizi de Biani, F. Inorganic Electrochemistry. Theory, Practice and Application, 2nd ed.; RSC: Cambridge, UK, 2003.

(16) Romanelli, M. Sim. Program Cu23-GPN1; University of Florence: Florence, Italy, 1995.

(17) (a) Mabbs, F. E.; Collins, D. Electron Paramagnetic Resonance of Transition Metal Compounds; Elsevier: New York, 1992. (b) Drago, R. S. Physical Methods for Chemists; Saunders College Publishing: New York, 1992.

(18) (a) Fabrizi de Biani, F.; Ienco, A.; Laschi, F.; Leoni, P.; Marchetti, F.; Marchetti, L.; Mealli, C.; Zanello, P. J. Am. Chem. Soc. 2005, 127, 3076-3089. (b) Margraf, G.; Kretz, T.; Fabrizi de Biani, F.; Laschi, F.; Losi, S.; Zanello, P.; Bats, J. W.; Wolf, B.; Removic-Langer, K.; Lang, M.; Prokofiev, A.; Assmus, W.; Lerner, H. W.; Wagner, M. Inorg. Chem. 2006, 45, 1277-1288. (c) Angelici, R. J.; Zhu, B.; Fedi, S.; Laschi, F.; Zanello, P. Inorg. Chem. 2007, 46, 10901-10906. (d) Fedi, S.; Zanello, P.; Laschi, F.; Ceriotti, A.; El Afefey, S. J. Solid State Electrochem. 2009, 13, 1497-1504.

(19) Improta, R.; Barone, V. Chem. Rev. 2004, 104, 1231-1254.

(20) Our first choice has been the PM6 method (MOPAC2009: Stewart J. J. P. Stewart Computational Chemistry, version 9.282W; web HTTP://OpenMOPAC.net. General reference for PM6: Stewart, J. J. P. J. Mol. Model. 2007, 13, 1173-1213 ). In fact, unrestricted calculations are possible with PM6; therefore, a reasonable description of the spin density, taking into account also a spin polarization mechanism, was expected. Unfortunately, we discovered that PM6 does not yet have a good performance for rhodium, and all of the calculations suffered from severe problems (spin contamination, convergence).

(21) Mealli, C.; Proserpio, D. M. J. Chem. Educ. 1990, 67, 399-402.

(22) HyperChem(TM) Professional 8.0; Hypercube, Inc.: Gainesville, FL, 2007.

(23) Normal distribution $N\left(\mu, \sigma^{2}\right): \mu=$ eigenvalue; $\sigma^{2}=0.005$.

(24) Shriver, D. F.; Dredzon, M. A. The Manipulation of Air-Sensitive Compounds, 2nd ed.; Wiley: New York, 1986.

(25) Braunstein, P.; Lehner, H.; Matt, D. Inorg. Synth 1990, 27, 218221.

(26) Sheldrick, G. M. SADABS; University of Göttingen: Göttingen, Germany, 2003.

(27) Altomare, A.; Burla, M. C.; Camalli, M.; Cascarano, G. L.; Giacovazzo, C.; Guagliardi, A.; Moliterni, A. G. G.; Polidori, G.; Spagna, R. J. Appl. Crystallogr. 1999, 32, 115-119.

(28) Sheldrick, G. M. SHELX-97 Programs for Crystal Structure Analysis, release 97-2; University of Göttingen: Göttingen, Germany, 1997.

(29) Sheldrick, G. M. Acta Crystallogr. 2010, 64A, 112-122.

(30) Origin; OriginLab, Northampton, MA. 